\title{
Direct genotyping of single pollen grains of a self-compatible mutant of Japanese pear (Pyrus pyrifolia) revealed inheritance of a duplicated chromosomal segment containing a second $S$-haplotype
}

\author{
Nobuko Mase $\cdot$ Yutaka Sawamura \\ Toshiya Yamamoto $\cdot$ Norio Takada • \\ Sogo Nishio $\cdot$ Toshihiro Saito $\cdot$ Hiroyuki Iketani
}

Received: 14 March 2014 / Accepted: 27 May 2014/Published online: 12 June 2014

(C) The Author(s) 2014. This article is published with open access at Springerlink.com

\begin{abstract}
Radiation mutant 415-1, which is the first known diploid pollen-part self-compatible mutant of pears (Pyrus spp.), has a decreased ability to produce pollen. To determine whether the self-compatibility trait is associated with this defect, we directly analyzed the genotypes of individual pollen grains by using polymerase chain reaction amplification of DNA from single pollen grains. We isolated single pollen grains from 415-1 and succeeded in genotyping the $S$-RNase gene and three simple sequence repeat (SSR) markers in linkage group 17. Out of 173 individual pollen grains, 28 (16\%) were $S$-heteroallelic. These pollen grains had two alleles each of the $S$-RNase gene and of two linked SSR loci, all on a duplicated chromosomal segment, but only one allele of a non-duplicated locus farther away on the same chromosome. The segregation ratio of each marker in the pollen from 415-1 was approximately the same as that observed in outcross progeny. This suggests that the decrease in frequency of pollen with the duplicated $S$-haplotype occurred during meiosis or
\end{abstract}

N. Mase $(\bowtie) \cdot$ Y. Sawamura · T. Yamamoto .

N. Takada $\cdot$ S. Nishio $\cdot$ T. Saito $\cdot$ H. Iketani

NARO Institute of Fruit Tree Science, National

Agriculture and Food Research Organization,

2-1 Fujimoto, Tsukuba, Ibaraki 305-8605, Japan

e-mail:nobuko@affrc.go.jp

N. Mase - T. Yamamoto $\cdot$ H. Iketani

Graduate School of Life and Environmental Science, University of Tsukuba, Tennoudai 1-1-1, Tsukuba,

Ibaraki 305-8572, Japan pollen formation, but that the probability of fertilization by $S$-heteroallelic pollen is equal to that of single-allelic pollen. However, the partial sterility in 415-1 can also be attributed to one or more unidentified lethal mutations unlinked to the duplicated segment encompassing the $S$ haplotype. Single-pollen genotyping can be used in a variety of applications in genetic research because in cases where all pollen genotypes are proportionately represented in the progeny, segregation ratios can be obtained without producing the next generation.

Keywords Duplicated $S$-haplotype $\cdot$ Pollen-part self-compatible mutant $\cdot$ Pyrus pyrifolia $\cdot$ Selfincompatibility $\cdot S$-heteroallelic pollen $\cdot$ Single-pollen genotyping

\section{Introduction}

Self-incompatibility in flowering plants is a genetic system that prevents inbreeding and promotes genetic diversity (de Nettancourt 2001). Most of the important fruit crops in the Rosaceae, such as Malus, Pyrus (subtribe Pyrinae), and Prunus, exhibit $S$-RNase-based self-incompatibility controlled by at least two tightly linked genes, one style-specific gene and one or more pollen-specific genes, located at the complex $S$-locus. The stylar factor in all members of the Rosaceae studied to date is $S$-RNase. In contrast, the pollen factors in the Rosaceae are currently classified into two different types. In Prunus, there is a single F-box protein called 
SLF (S-locus F-box) (Entani et al. 2003) or SFB ( $S$ haplotype-specific F-box protein) (Ushijima et al. 2003) that is predicted to recognize self $S$-RNase, whereas in the Pyrinae, there are multiple F-box proteins called SFBB ( $S$ locus F-box brothers) (Sassa et al. 2007; Minamikawa et al. 2010) that are predicted to collaborate in recognizing non-self $S$-RNase (Kakui et al. 2011; Saito et al. 2012). In either case, these plants require cross pollination with other cultivars to set fruit. In monocultivar orchards for commercial production of Japanese pear (Pyrus pyrifolia), artificial fertilization is performed using compatible pollen collected from other cultivars to improve fruit quality and quantity (Sakamoto et al. 2009). So far, the only known self-compatible mutant useful for breeding purposes was identified in 'Osa-Nijisseiki', a bud sport of 'Nijisseiki'. It exhibits style-specific inactivation of the $S_{4}$-allele, thus it is a stylar-part self-compatible mutant (SPM) (Sassa et al. 1997). This cultivar has been used in agricultural production, as breeding material, and as experimental material for studying the genes controlling self-incompatibility (Norioka et al. 1996). However, the pollen of 'Osa-Nijisseiki' (and other SPM materials bred from it) still maintains self-incompatibility, so it cannot be used to pollinate existing self-incompatible cultivars having the same $S$-genotypes. Therefore, to produce fruits without artificial pollination, all trees in an orchard eventually need to be replaced by self-compatible ones, so other new SPM cultivars are highly desired. At present, since 'Osa-Nijisseiki' is the only genetic material available for breeding of self-compatible cultivars in Japanese pear, SPM cultivars originated from 'Osa-Nijisseiki' often resemble each other in characteristics such as eating quality and harvest time. Moreover, it is likely that inbreeding depression will occur in the progeny of crosses between cultivars originating from 'Osa-Nijisseiki' or 'Nijisseiki' in the future (Sato et al. 2008).

On the other hand, a pollen-part self-compatible mutant (PPM) can produce omni-potential pollen, i.e., pollen compatible with self-incompatible styles of all $S$-haplotypes including its own. A PPM that produced enough viable pollen could be used as a pollinator by planting it in a limited part of the orchard. However, all hitherto-known PPMs in the Pyrinae have been polyploids that often exhibit a reduction in pollen tube growth and pollen germination rate (Lewis and Modlibowska 1942; Adachi et al. 2009). Hence, they are not suitable for use as pollinators or for breeding material.
Recently, our research group has produced breeding selection 415-1, a PPM derived by using pollen from $\gamma$-irradiated 'Kosui' (self-incompatible) to pollinate non-irradiated 'Kosui' (Sawamura et al. 2013). It is deduced to be a diploid by means of flow cytometry, but genetic analysis indicates that it has a segmental duplication encompassing the $S_{5}$-haplotype that is usually inherited together with the $S_{4}$ chromosome. Thus, this selection is predicted to produce $S$-heteroallelic pollen grains that are capable of breaking down self-incompatibility by competitive interaction between the two different $S$ factors in the pollen grain (Mase et al. 2014). It is an important material for breeding as well as for analyzing the mechanism of competitive interaction, which is now hypothesized to be caused by non-self recognition of $S$-RNase by two different sets of pollen $S$-determinants in a single pollen tube (Kubo et al. 2010; de Franceschi et al. 2012). However, the direct detection of two $S$-haplotypes in a single pollen grain of a PPM plant has not previously been achieved.

To be of practical use, PPM cultivars should produce fairly large amounts of self-compatible pollen. However, pollen-sterile or low-fertility mutants are often found in progeny derived from irradiated pollen (Vizir et al. 1994; Naito et al. 2005). Moreover, inbreeding can induce pollen sterility through accumulation of deleterious genes. Indeed, the pollen production of 415-1 is lower than that of normal (pollen-fertile) cultivars. To address this limitation, we plan to cross 415-1 with fertile cultivars and select progeny that produce large quantities of pollen, especially with a high frequency of the duplicated $S$ haplotype.

In most studies, the segregation ratio of alleles in germ cells has been estimated from the ratio of corresponding genotypes in the progeny. The frequency of 415-1 progeny with a duplicated $S$-haplotype is low (14\%) (Mase et al. 2014). This decrease in viability could be occurring at one or more stages from meiosis to the 1-year-old seedling stage, which we used for progeny analysis. Thus, the $S$-haplotype frequency in the pollen of PPM mutant 415-1 could be different from that of the progeny. For these reasons, it is important to determine the frequency of the duplicated $S$-haplotype in pollen directly, enabling us to select the most appropriate individual(s) without genotyping a large number of progenies. 
Single-pollen genotyping has been performed successfully by some research groups (Petersen et al. 1996; Suyama et al. 1996; Matsunaga et al. 1999) based on the procedure of polymerase chain reaction (PCR) amplification of DNA from a single animal cell or sperm (Li et al. 1988; Cui et al. 1989). The original methods are laborious and time-consuming, especially in the pollen manipulation and DNA extraction steps. Recently, a simpler method for direct genotyping of multiple microsatellite (simple sequence repeat, SSR) markers in single pollen grains was developed by Matsuki et al. (2007). This research group revealed that strict self-incompatibility maintains the genetic diversity of wild Japanese chestnut by determining the SSR alleles of individual pollen on the styles and thus the genotypes of the seeds produced (Hasegawa et al. 2009).

In this study, we identified the $S$-haplotype and SSR genotype of individual pollen from 415-1, and we observed the pollen morphology of $415-1$ and a normal (self-incompatible) cultivar 'Kosui'. We compared the occurrence of the duplicated $S$-haplotype in pollen and progeny and we examined the possible involvement of the duplicated haplotype in the pollen morphology and pollen-producing capability of 415-1.

\section{Materials and methods}

\section{Collection of pollen grains}

The PPM selection 415-1 and the normal (selfincompatible) cultivar 'Kosui' were sampled from the orchard of the NARO Institute of Fruit Tree Science (NIFTS). Anthers of 415-1 and 'Kosui' were collected from flower buds 1 day prior to opening and dried in an incubator $\left(25{ }^{\circ} \mathrm{C}, 35 \%\right.$ relative humidity) until dehiscence, which usually took about $40 \mathrm{~h}$, then stored at $-80{ }^{\circ} \mathrm{C}$ until used.

DNA extraction from individual pollen grains

The DNA extraction method was that of Suyama (2011), with some modifications. In a clean booth (ACR-321C [Airtech Japan, LTD., Japan]), dried pollen grains (with anthers) of 415-1 were suspended in a drop $(20 \mu \mathrm{L})$ of $2 \times$ PCR buffer $(20 \mathrm{mM}$ Tris- $\mathrm{HCl}$ [pH 8.0], $100 \mathrm{mM} \mathrm{KCl,} 3 \mathrm{mM} \mathrm{MgCl} 2$ ) with $0.005 \%$ sodium dodecyl sulfate (SDS) and $0.04 \%$
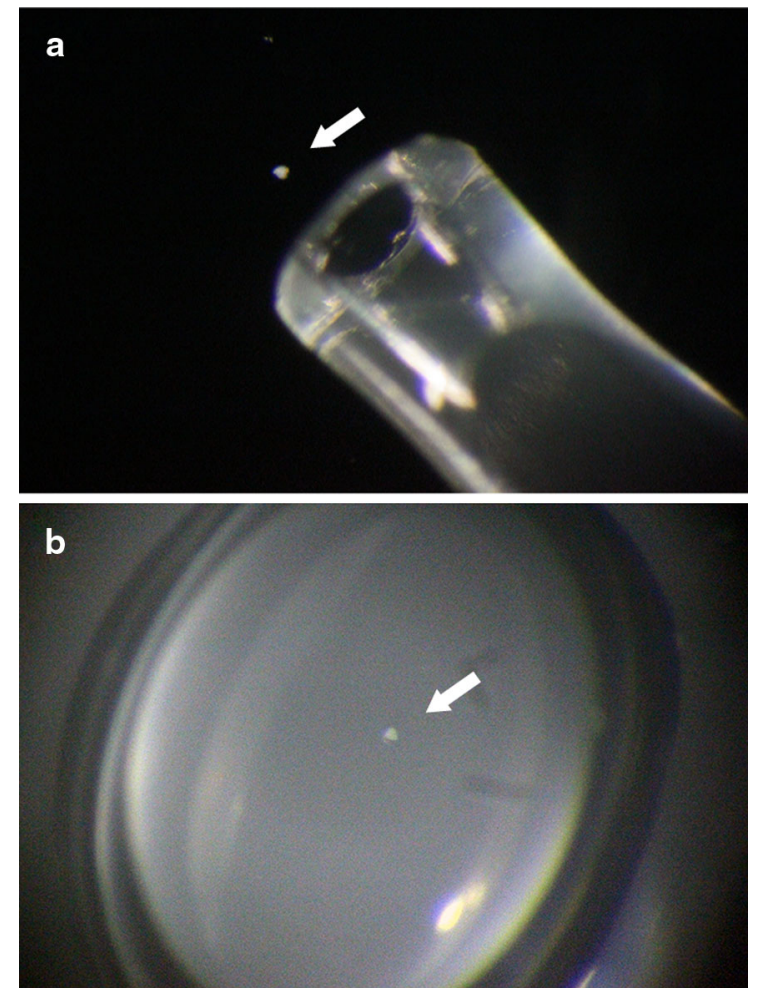

Fig. 1 Manipulation of a single pollen grain (indicated by arrow). a A single pollen grain before transfer to a PCR tube. Micropipette tips with outer and inner diameter of 750 and $450 \mu \mathrm{m}$, respectively, were used for transfer. b A single pollen grain of 415-1 transferred to the inner wall of a PCR tube

2-mercaptoethanol on a disposable Petri dish. Under a stereomicroscope with a $6-50 \times$ zoom lens, a few pollen grains in $2 \times$ PCR buffer were transferred into a clean drop of $2 \times$ PCR buffer using a micropipette and tips with $0.5-10 \mu \mathrm{L}$ capacity. For each reaction, a single pollen grain, filled with cytoplasm (pale yellow) and not abnormally small (Fig. 1a), was picked up in $2 \times$ PCR buffer (less than $2 \mu \mathrm{L}$ ) and put into a $0.2-\mathrm{mL}$ PCR tube. The tube was then checked to ensure that only a single grain had been transferred (Fig. 1b), $2 \mu \mathrm{L}$ of lysis buffer containing $0.015 \%$ SDS and $0.2 \mu \mathrm{g} / \mu \mathrm{L}$ proteinase $\mathrm{K}$ was added, and the tube was incubated at $50{ }^{\circ} \mathrm{C}$ for $60 \mathrm{~min}$ followed by $95{ }^{\circ} \mathrm{C}$ for $10 \mathrm{~min}$.

\section{Determination of S-RNase and microsatellite genotypes}

Multiplex PCR was performed in a $10-\mu \mathrm{L}$ volume with a QIAGEN Multiplex PCR kit (QIAGEN, Germany) containing total DNA extracted from a single pollen 


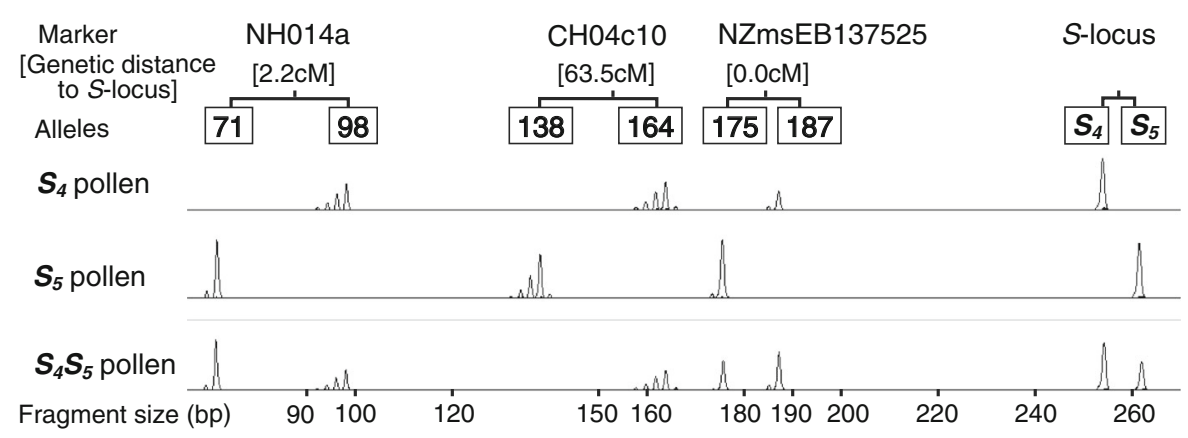

Fig. 2 S-RNase and microsatellite alleles detected by multiplex PCR from single pollen grains of 415-1. Fragment sizes (bp) of an internal DNA size standard (GeneScan 400 HD ROX Size Standard) are indicated below

grain (up to $4 \mu \mathrm{L}$ ), $1 \times$ QIAGEN Multiplex PCR mix, and the following six pairs of primers. A 6-FAM labeled FTQQYQ primer (Ishimizu et al. 1999) and a newly designed non-labeled primer (5'-RYgtgcatgaaaatctatg- $\left.3^{\prime}\right)$ were used to amplify a $254-$ or 262-bp fragment of the $S_{4}$ - or $S_{5}$-RNase gene, respectively (Fig. 2). Five sets of fluorescently labeled (6-FAM, HEX, or NED) forward primers and nonlabeled reverse primers were used to genotype SSR loci mapped to the same linkage group as the $S$-haplotype (linkage group [LG] 17) of pear or apple (Malus $\times$ domestica Borkh.). These SSR markers consisted of three pear SSRs, NH014a (Yamamoto et al. 2002), TsuENH028 (Nishitani et al. 2009), and TsuENH154 (GenBank accession number AB735184), and two apple SSRs, NZmsEB137525 (Celton et al. 2009) and CH04c10 (Liebhard et al. 2002). To establish the reaction conditions, $0.2 \mu \mathrm{M}$ of each primer set was used in a single reaction, and then the concentration of each primer was adjusted to improve amplification efficiency. Amplification was carried out using a Veriti ${ }^{\circledR}$ Thermal Cycler (Applied Biosystems, USA) under the following conditions: initial activation at $94{ }^{\circ} \mathrm{C}$ for $15 \mathrm{~min}$, followed by 37 cycles of denaturation at $94{ }^{\circ} \mathrm{C}$ for $30 \mathrm{~s}$, annealing at $54{ }^{\circ} \mathrm{C}$ for $90 \mathrm{~s}$, and extension at $72{ }^{\circ} \mathrm{C}$ for $60 \mathrm{~s}$, followed by a final extension at $72{ }^{\circ} \mathrm{C}$ for $10 \mathrm{~min}$. The PCR products were separated and detected using an ABI PRISM 3100 Genetic Analyzer (Applied Biosystems). The sizes of the amplified bands were determined based on an internal DNA size standard (GeneScan 400 HD ROX Size Standard [Applied Biosystems]) with GeneScan Software (Applied Biosystems). Allele size data (in bp) were rounded down to the nearest whole number.
Microscopic observations

Dried pollen of 415-1 and 'Kosui' was suspended in $n$-hexane and filtered through a $50-\mu \mathrm{m}$ nylon mesh (Partec Gmbh, Germany) to remove anther tissues. After drying at room temperature, pollen was suspended in aniline blue lactophenol stain (Hauser and Morrison 1964), and then incubated for $30 \mathrm{~min}$ at room temperature. Twenty microlitre of suspension was dropped onto a glass slide and observed at $100 \times$ magnification under a light microscope (Axioskop 50 [Carl Zeiss, Germany]). The images were captured with an AxioCam Mrc5 camera and processed with AxioVision 4.5Ac software (Carl Zeiss). Cross-sectional areas were measured for approximately 200 pollen grains of each cultivar with SmartGrain software (Tanabata et al. 2012).

\section{Results}

\section{S-RNase and microsatellite genotyping from single} pollen grains

We successfully amplified and genotyped DNA fragments representing the $S$-RNase gene and three SSR loci. The optimized concentrations of primers in each pair were $0.15 \mu \mathrm{M}$ for $S$-RNase, $0.08 \mu \mathrm{M}$ for NH014a, $0.06 \mu \mathrm{M}$ for NZmsEB137525, and $0.2 \mu \mathrm{M}$ for CH04c10. The amplifications of TsuENH154 and TsuENH028 were unstable, so these two primer sets were excluded from the genotyping.

PCR reactions were performed with 316 pollen grains from 415-1, and amplification of all four loci $(S$ - 
Table 1 Frequency of S-RNase alleles in pollen and 1-yearold offspring of 415-1

\begin{tabular}{lrrll}
\hline Genotype & $S_{4}$ & \multicolumn{1}{c}{$S_{5}$} & $S_{4} S_{5}$ & Total \\
\hline Pollen & 10 & 135 & 28 & 173 \\
Offspring $^{\mathrm{a}}$ & 2 & 87 & 14 & 103 \\
\hline
\end{tabular}

${ }^{a} \mathrm{~F}_{1}$ plants obtained from a cross to the self-incompatible cultivar 'Niitaka' $\left(S_{3} S_{9}\right)$; data from Mase et al. (2014)

RNase and three SSR loci) was successful for 206 (65\%). Success in isolating single pollen grains with a single $S$-haplotype per haploid genome was confirmed by detection of only one allele of each of the four loci in a single amplification reaction. On the other hand, successful isolation of an $S$-heteroallelic pollen grain was confirmed by detection of two alleles of S-RNase and of two SSR loci (NH014a and NZmsEB137525), all on the duplicated chromosomal segment in 415-1, and detection of one allele of a non-duplicated SSR locus ( $\mathrm{CH04c10)}$ farther away on the same chromosome (Fig. 2).

Five samples $(1.6 \%)$ that had two alleles of $\mathrm{CH} 04 \mathrm{c} 10$ (non-duplicated locus) were determined to be from having two different pollen grains in one amplification product. This frequency was very low and nearly the same $(2.2 \%)$ as in the previous study (Hasegawa et al. 2009), and these samples were considered to be insignificant in our determination of allelic frequencies. We could not decide the genotype of 33 pollen grains that had allelic compositions inconsistent with the expectations for either the $S$-homoallelic or $S$-heteroallelic situation. This result could be due to failure of amplification of one of two alleles, recombination between alleles of duplicated loci in the $S$-heteroallelic pollen, or amplification of DNA from two different pollen grains.

Collectively, the haplotypes of 173 individual pollen grains were successfully analyzed. The allelic frequency of $S$-RNase in pollen from 415-1 was $S_{4}: S_{5}: S_{4} S_{5}=10: 135: 28$ (Table 1). In $103 \mathrm{~F}_{1}$ progeny obtained from a cross with the self-incompatible cultivar 'Niitaka' $\left(S_{3} S_{9}\right)$, the $S$-phenotypes from 415-1 segregated in a ratio of $2 S_{4}: 87 S_{5}: 14 S_{4} S_{5}$ (Mase et al. 2014; Table 1). There was no significant difference in the allelic frequency of $S$-RNase in pollen and offspring from $415-1$ ( $p=0.25$ for Fisher's exact test, Table 1).
Pollen morphology

We compared the size and viability of pollen grains from normal cultivar 'Kosui' and PPM selection 415-1. Pollen grains of 'Kosui' were uniform in size and shape. $95 \%$ were large, viable (fully stained) and roundish-triangular, and the mean cross-sectional area was $114.2 \pm 10.5 \mu \mathrm{m}^{2}$. Five percent were relatively small $\left(47.1 \pm 3.1 \mu^{2}\right)$, shrunken, and unstained or partially stained (Fig. 3a, c). In contrast, pollen grains of 415-1 were non-uniform in size, shape, and staining intensity. The mean area of fully stained and round or roundish-triangular pollen $(65 \%)$ was $104 \pm 21.6 \mu^{2}$, whereas the mean area of unstained or partially stained and dimpled or shrunken pollen (35\%) was $49.7 \pm 8.9 \mu \mathrm{m}^{2}$ (Fig. 3b, d).

\section{Discussion}

DNA amplification from a single pollen grain

In this study, DNA of pollen grains of 415-1 was readily isolated by suspending pollen in $2 \times$ PCR solution containing a low concentration of SDS and 2-mercaptoethanol, instead of sterile water or sterile water-based solution as in previous methods (Hasegawa et al. 2009; Suyama 2011). This improvement was observed to reduce the frequency of pollen bursting (data not shown), probably leading to less DNA degradation. It takes only 60-90 min to collect 45 pollen grains and transfer individual grains into different PCR tubes for one experiment. It was important to keep the time before DNA extraction as short as possible to succeed in PCR amplification from pollen grains of Japanese pear.

We had only six markers available to test (only four of which gave reliable amplification in this experiment) because of the high homozygosity in 415-1 and a consequent paucity of heterozygous SSR loci. However, more SSR markers will be available for pollen genotyping of later progenies, as successful amplification of a maximum of 104 AFLP markers was reported by Aziz and Sauve (2008).

Pollen size and fertility of $415-1$

Most pollen grains of 'Kosui' were uniform in size, shape, and viability and had the standard morphology 
Fig. 3 Pollen viability and size of 415-1 and 'Kosui'. Aniline blue staining of pollen grains from normal (self-incompatible) cultivar 'Kosui' (a) and PPM selection 415-1 (b); scale bar, $20 \mu \mathrm{m}$. Histogram of cross-sectional areas of pollen grains $\left(\mu \mathrm{m}^{2}\right)$ of 'Kosui' (c) and 415-1 (d). Fully stained grains are shown in filled bars and unstained or partially stained grains are shown in open bars. The frequency of pollen grains of each size is expressed as a percentage of the total number of pollen grains $(n=222$ in $\mathbf{c}$; $n=214$ in d)
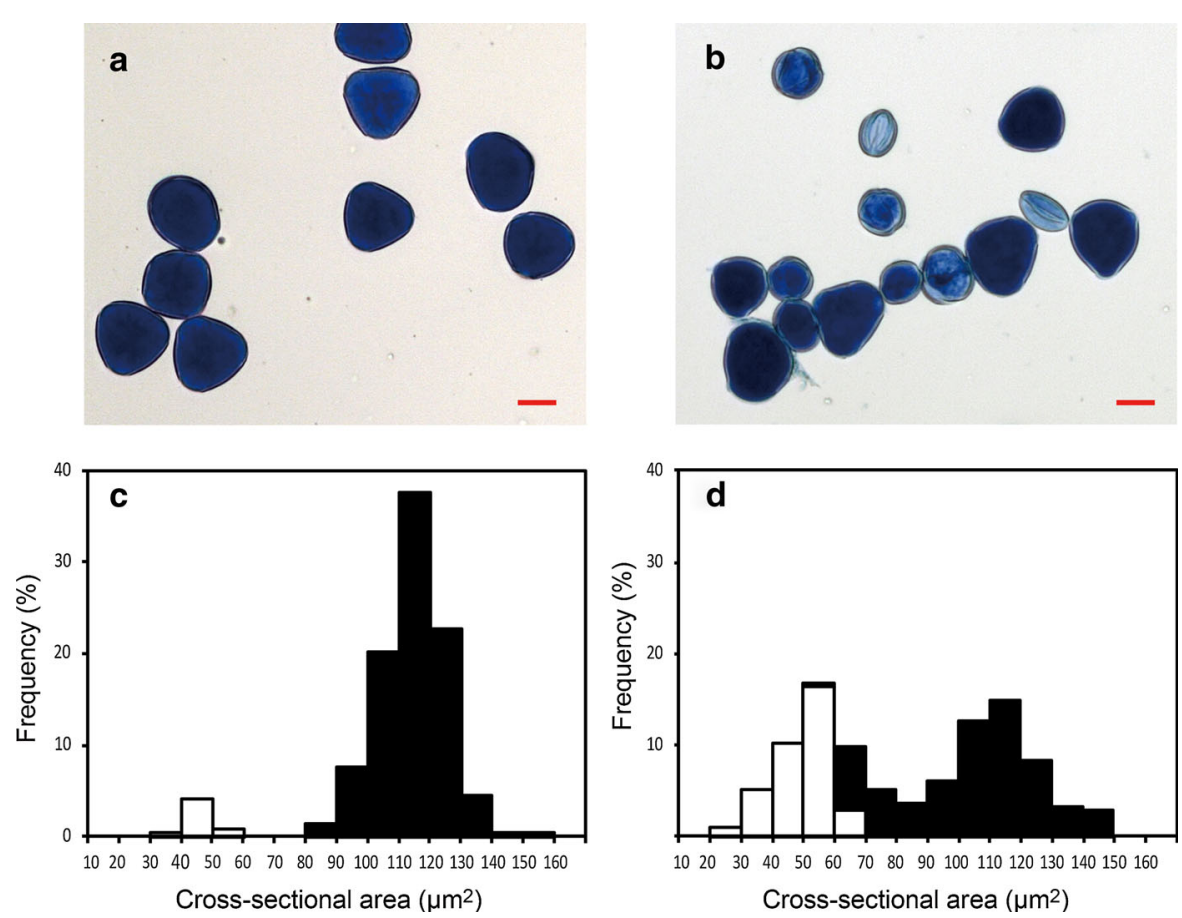

of mature pollen of Japanese pear (Okusaka and Hiratsuka 2009). On the other hand, the histogram of pollen size of 415-1 showed two approximately uniform peaks, one at the standard size and the other at a smaller size (Fig. 3). The former consisted of standard viable pollen, and the latter contained sterile pollen that was empty or only partially full. In many cases, aborted pollen comes from abnormal meiosis during gamete formation due to polyploidy, aneuploidy, or a genetic defect that controls the distribution of chromosomes (Ramsey and Schemske 2002; Consiglino et al. 2007). Consequently, the aborted grains do not have a complete haploid genome (Deng and Wang 2007). In this study, we isolated and used only larger, filled pollen grains (presumed to have a complete haploid genome) for PCR amplification.

This procedure enabled us to successfully detect normal-size pollen with a duplicated $S$-haplotype. Overall, the segregation ratio of markers in the normal pollen grains of 415-1 was approximately the same as that observed in the progeny ( $p=0.25$ for Fisher's exact test; Table 1). Looking more specifically at each class, the frequencies of the single-allelic $\left(S_{5}\right)$ and heteroallelic $\left(S_{4} S_{5}\right)$ classes were approximately the same in pollen and offspring. However, the frequency of $S_{4}$ pollen grains $(5.8 \%)$, which are assumed to be produced by loss of the duplicated $S_{5}$ segment by deletion or recombination from meiotic cells with the $S_{4} S_{5}$ chromosome, appeared to be higher than that of $S_{4}$ offspring $(1.9 \%)$. If real, this difference may indicate that the recombination frequency between the duplicated $S_{5}$ and the original $S$-haplotype during meiosis is higher than that originally predicted by segregation in the offspring. Another possibility is that the viability of $S_{4}$ pollen (meiotic cells) is higher than that of $S_{4} S_{5}$ during the processes of meiosis and pollen formation because of one or more detrimental genes in the duplicated $S_{5}$ segment. Either of these explanations require the assumption that $S_{4}$ pollen is less viable than $S_{4} S_{5}$ pollen in the steps following pollen production (i.e., from pollen germination to seed germination), because the frequencies of pollen and offspring containing $S_{4} S_{5}$ were similar. In other words, the segmental duplication does not decrease the likelihood of fertilization when present in an otherwise normal pollen grain. This indicates that the decrease in frequency of pollen with the duplicated $S$-haplotype occurred during meiosis or pollen formation, but it is unclear whether this duplication is the only reason for the defect in pollen production seen in 415-1. Because the paternal parent tree of 415-1 has been irradiated daily for more than 30 years, many other detrimental 
mutations are expected to have accumulated throughout the genome that may play a negative role in pollen formation, regardless of the pollen $S$-haplotype.

\section{Conclusions}

Using single-pollen genotyping, we succeeded in a straightforward proof of the presence of $S$-haplotype duplication in pollen grains of 415-1 that did not require analysis of progenies. We also showed that the segregation ratio of marker alleles in the pollen was nearly identical to that in the progeny. Under such circumstances, it is possible through pollen genotyping to reveal the segregation ratio of alleles at each locus rapidly and without generating progeny. On the other hand, a difference in the segregation ratio of alleles between pollen and progeny would suggest that pollen with a specific allele at the locus of interest might be less competitive. Single-pollen genotyping could also be used to perform fine-scale mapping in the flanking region of a gene of interest in a fruit or forest tree species without spending the enormous time, cost, and effort to obtain a sufficient number of progeny; this approach has been used with sperm cells of large animal species and humans (Cui et al. 1989; Windemuth et al. 1998).

Our next step is to determine the pollen productivity, fertility, and $S$-haplotype segregation in pollen of materials derived from 415-1 and known to carry the duplicated $S$-haplotype. Utilization of this method will simplify the selection of breeding materials with a duplicated $S$-haplotype that produce adequate amounts of pollen and are thus suitable for use in the production of pollen-part self-compatible cultivars.

Single-pollen genotyping and sequencing have so far been utilized only in molecular taxonomy and ecological genetics (Zhou et al. 2007; Ito et al. 2008; Hirota et al. 2013). However, we think that singlepollen analysis has the potential for important applications in breeding science, and we expect further utilization of this method.

Acknowledgments We thank Dr. Y. Suyama of the Graduate School of Agricultural Science, Tohoku University, for technical guidance on single-pollen genotyping. This work was supported in part by the Budget for Nuclear Research of the Ministry of Education, Culture, Sports, Science and Technology in Japan, based on the screening and counseling by the Atomic Energy Commission.
Open Access This article is distributed under the terms of the Creative Commons Attribution License which permits any use, distribution, and reproduction in any medium, provided the original author(s) and the source are credited.

\section{References}

Adachi Y, Komori S, Hoshikawa Y, Yanaka N, Abe K, Bessho H, Watanabe M, Suzuki A (2009) Characteristics of fruiting and pollen tube growth of apple autotetraploid cultivars showing self-compatibility. J Jpn Soc Hortic Sci 78:402-409

Aziz AN, Sauve RJ (2008) Genetic mapping of Echinacea purpurea via individual pollen DNA fingerprinting. Mol Breed 21:227-232

Celton JM, Tustin DS, Chagné D, Gardiner SE (2009) Construction of a dense genetic linkage map for apple rootstocks using SSRs developed from Malus ESTs and Pyrus genomic sequences. Tree Genet Genomes 5:93-107

Consiglino F, Carputo D, Frusciante L, Monti LM, Conicella C (2007) Meiotic mutations and crop improvement. In: Janick J (ed) Plant breeding reviews. Wiley, Hoboken, pp 163-214

Cui X, Li H, Goradia T, Lange K, Kazazizan HH, Galas D, Arnheim N (1989) Single-sperm typing: determination of genetic distance between the $\mathrm{GCu}$-globin and parathyroid hormone loci by using the polymerase chain reaction and allele-specific oligomers. Proc Nat Acad Sci USA 86:9389-9393

de Franceschi P, Dondini L, Sanzol J (2012) Molecular bases and evolutionary dynamics of self-incompatibility in the Pyrinae (Rosaceae). J Exp Bot 63:4015-4032

de Nettancourt D (2001) Incompatibility and incongruity in wild and cultivated plants. Springer-Verlag, Berlin

Deng ZY, Wang T (2007) OsDMC1 is required for homologous pairing in Oryza sativa. Plant Mol Biol 65:31-42

Entani T, Iwano M, Shiba H, Che FS, Isogai A, Takayama S (2003) Comparative analysis of the self-incompatibility ( $S$-) locus region of Prunus mume: identification of a pollen-expressed F-box gene with allelic diversity. Genes Cells 8:203-213

Hasegawa Y, Suyama Y, Seiwa K, Tsumura Y (2009) Pollen donor composition during the early phases of reproduction revealed by DNA genotyping of pollen grains and seeds of Castanea crenata. New Phytol 182:994-1002

Hauser EJP, Morrison JH (1964) The cytochemical reduction of nitro blue tetrazolium as an index of pollen viability. Am J Bot 51:748-752

Hirota SK, Nitta K, Suyama Y, Kawakubo N, Yasumoto AA, Yahara T (2013) Pollinator-mediated selection on flower color, flower scent and flower morphology of Hemerocallis: evidence from genotyping individual pollen grains on the stigma. PLoS ONE. doi:10.1371/journal.pone.0085601

Ishimizu T, Inoue K, Shimonaka M, Saito T, Terai O, Norioka S (1999) PCR-based method for identifying the $S$-genotypes of Japanese pear cultivars. Theor Appl Genet 98:961-967

Ito M, Suyama Y, Ohsawa TA, Watano Y (2008) Airbornepollen pool and mating pattern in a hybrid zone between Pinus pumila and P. parviflora var. pentaphylla. Mol Ecol 17:5092-5103 
Kakui H, Kato M, Ushijima K, Kitaguchi M, Kato S, Sassa H (2011) Sequence divergence and loss-of-function phenotypes of $S$ locus F-box brothers (SFBB) genes are consistent with non-self recognition by multiple pollen determinants in self-incompatibility of Japanese pear (Pyrus pyrifolia). Plant J 68:1028-1038

Kubo K, Entani T, Takara A, Wang N, Fields AM, Hua Z, Toyoda M, Kawashima S, Ando T, Isogai A, Kao T, Takayama S (2010) Collaborative non-self recognition system in S-RNase-based self-incompatibility. Science 330:796-799

Lewis D, Modlibowska I (1942) Genetical studies in pears. IV. Pollen-tube growth and incompatibility. J Genet 43: 211-222

Li H, Gyllensten UB, Cui X, Saiki RK, Erlich HA, Arnheim N (1988) Amplification and analysis of DNA sequences in single human sperm and diploid cells. Nature 335:414-417

Liebhard R, Gianfranceschi L, Koller B, Ryder CD, Tarchini R, van de Weg E, Gessler C (2002) Development and characterisation of 140 new microsatellites in apple (Malus $\times$ domestica Borkh.). Mol Breed 10:217-241

Mase N, Sawamura Y, Yamamoto T, Takada N, Nishio S, Saito T, Iketani H (2014) A segmental duplication encompassing $S$-haplotype triggers pollen-part self-compatibility in Japanese pear (Pyrus pyrifolia). Mol Breed 32:117-128

Matsuki Y, Isagi Y, Suyama Y (2007) The determination of multiple microsatellite genotypes and DNA sequences from a single pollen grain. Mol Ecol Notes 7:194-198

Matsunaga S, Schütse K, Donnison IS, Grant SR, Kuroiwa T, Kawano S (1999) Single pollen typing combined with laser-mediated manipulation. Plant J 20:371-378

Minamikawa M, Kakui H, Wang S, Kotoda N, Kikuchi S, Sassa H Koba T (2010) Apple $S$ locus region represents a large cluster of related, polymorphic and pollen-specific F-box genes. Plant Mol Biol 74:143-154

Naito K, Kusaba M, Shikazono N, Takano T, Tanaka A, Tanisaka T, Nishimura M (2005) Transmissible and nontransmissible mutations induced by irradiating Arabidopsis thaliana pollen with gamma-rays and carbon ions. Genetics 169:881-889

Nishitani C, Terakami S, Sawamura Y, Takada N, Yamamoto T (2009) Development of novel EST-SSR markers derived from Japanese pear (Pyrus pyrifolia). Breed Sci 59: 391-400

Norioka N, Norioka S, Ohnishi Y, Ishimizu T, Oneyama C, Nakanishi T, Sakiyama T (1996) Molecular cloning and nucleotide sequence of cDNAs encoding $S$-allele specific stylar RNases in a self-incompatible cultivar and its mutant of Japanese pear, Pyrus pyrifolia Nakai. J Biochem 120:335-345

Okusaka K, Hiratsuka S (2009) Fructose inhibits pear pollen germination on agar medium without loss of viability. Sci Hortic 122:51-55

Petersen G, Johansen B, Seberg O (1996) PCR and sequencing from a single pollen grain. Plant Mol Biol 31:189-191

Ramsey J, Schemske DW (2002) Neopolyploidy in flowering plants. Annu Rev Ecol Syst 33:589-639
Saito T, Sato T, Sawamura Y, Shoda M, Takasaki-Yasuda T, Kotobuki K (2012) Dual recognition of $S_{1}$ and $S_{4}$ pistils by $S_{4}^{s m}$ pollen in self-incompatibility of Japanese pear (Pyrus pyrifolia Nakai). Tree Genet Genomes 8:689-694

Sakamoto D, Hayama H, Ito A, Kashimura Y, Morigichi T, Nakamura Y (2009) Spray pollination as a labor-saving pollination system in Japanese pear (Pyrus pyrifolia (Burm. f.) Nakai): development of the suspension medium. Sci Hortic 119:280-285

Sassa H, Hirano H, Nishino T, Koba T (1997) Style-specific self-compatible mutation caused by deletion of the $\mathrm{S}-\mathrm{RNase}$ gene in Japanese pear (Pyrus serotina). Plant J 12:223-227

Sassa H, Kakui H, Miyamoto M, Suzuki Y, Hanada T, Ushijima K, Kusaba M, Hirano H, Koba T (2007) S locus F-box brothers: multiple and pollen-specific F-box genes with $S$ haplotype-specific polymorphisms in apple and Japanese pear. Genetics 175:1869-1881

Sato A, Sawamura Y, Takada N, Hirabayashi T (2008) Relationship between inbreeding coefficients and plant height of 1-year-old seedlings in crosses among Japanese pear (Pyrus pyrifolia Nakai) cultivars/selections. Sci Hortic 117:85-88

Sawamura Y, Mase N, Takada N, Sato A, Nishitani C, Abe K, Masuda T, Yamamoto T, Saito T, Kotobuki K (2013) A self-compatible pollen-part mutant of Japanese pear produced by crossing 'Kosui' with pollen from gamma-irradiated 'Kosui'. J Jpn Soc Hortic Sci 82:222-226

Suyama Y (2011) Procedure for single-pollen genotyping. In: Isagi Y, Suyama Y (eds) Single-pollen genotyping. Ecological research monographs, Springer, Tokyo, pp 7-15

Suyama Y, Kawamuro K, Kinoshita I, Yoshimura K, Tsumura Y, Takahara H (1996) DNA sequence from a fossil pollen of Abies spp. from Pleistocene peat. Genes Genet Syst 71:145-149

Tanabata T, Shibaya T, Hori K, Ebana K, Yano M (2012) SmartGrain: high-throughput phenotyping software for measuring seed shape through image analysis. Plant Physiol 160:1871-1880

Ushijima K, Sassa H, Dandekar AM, Gradziel TM, Tao R, Hirano H (2003) Structural and transcriptional analysis of the self-incompatibility locus of almond: identification of a pollen-expressed F-box gene with haplotype-specific polymorphism. Plant Cell 15:771-781

Vizir IY, Anderson ML, Wilson ZA, Mulligan BJ (1994) Isolation of deficiencies in the Arabidopsis genome by $\gamma$ irradiation of pollen. Genetics 137:1111-1119

Windemuth C, Simianer H, Lien S (1998) Fitting genetic mapping functions based on sperm typing: results for three chromosomal segments in cattle. Anim Genet 29:425-434

Yamamoto T, Kimura T, Shoda M, Ban Y, Hayashi T, Matsuta N (2002) Development of microsatellite markers in Japanese pear (Pyrus pyrifolia Nakai). Mol Ecol Notes 2:14-16

Zhou LJ, Pei KQ, Zhou B, Ma KP (2007) A molecular approach to species identification of Chenopodiaceae pollen grains in surface soil. Am J Bot 94:477-481 